\title{
FAILURE OF A PRECAST RC BUILDING DUE TO EMILIA- ROMAGNA EARTHQUAKES
}

\author{
Ercolino M. ${ }^{(a)}$, Magliulo G. ${ }^{(*)(b)}$, Manfredi G. ${ }^{(b)}$ \\ (a) University of Greenwich, Department of Engineering Science, Central Avenue, Chatham, ME4 4TB, London, United \\ Kingdom \\ (b) University of Naples Federico II, Department of Structures for Engineering and Architecture, \\ Via Claudio 21, 80125 Naples, Italy \\ M.ercolino@greenwich.ac.uk,gmagliul@unina.it,gamanfre@unina.it
}

\begin{abstract}
Two 5.9 $\mathrm{M}_{\mathrm{w}}$ and 5.8 $\mathrm{M}_{\mathrm{w}}$ earthquakes hit Emilia-Romagna region on May 2012. Most of the precast RC one-story structures exhibited significant damage, causing huge economic losses as well as deaths. These events produced in-situ observations and data to develop a deeper knowledge on the seismic behavior of this structural typology.

This paper deals with the seismic assessment of a real precast RC industrial building with friction connections. The structure is located in Emilia-Romagna region and it was severely damaged during the second seismic event on May $29^{\text {th }}$. Structural columns exhibited cracking and yielding at the base as well as significant rotations along one direction. Moreover, relative displacements were recorded in both beam-to-column connections and in roof-to-beam connections and several loss of support phenomena occurred for the roof elements.

A detailed nonlinear structural model is defined in OpenSees code and nonlinear dynamic analyses are performed with the recorded accelerations time-histories of the two seismic events. By comparing the numerical results with the actual response of the structure, the adopted model is validated and the main damage typologies are also justified.
\end{abstract}

KEYWORDS: precast structure, earthquake-induced collapse, friction connection, nonlinear dynamic analysis

\section{INTRODUCTION}

On May 2012 two earthquakes hit Emilia-Romagna region (Northern Italy) and a huge number of existing precast RC one-story buildings was severely damaged. In some previous seismic events, the seismic vulnerability of precast RC buildings was already demonstrated, such as during Kocaeli earthquake (Turkey, 1999) [1] and L'Aquila earthquake (Italy, 2009) [2, 3]. However, in Emilia- 
Romagna the large number of damaged structures underlined the relevance of the seismic safety of this structural typology. In this part of the country, most of the precast structures hosted industrial and commercial activities and their collapse/damage was one of the main causes of the huge economic losses [4]. In order to reduce the economic impact, hence, the retrofitting of these structures was one of the most important actions during the emergency phase, aimed at restoring the activities/production within short time period.

From a scientific point of view, the widespread damage caused the availability of a huge number of data and field observations about the seismic response of precast RC structures, built in Northern Italy in the second half of the twentieth century and in the first years of the twenty-first century. The first evidence of the field surveys pointed out the presence of common deficiencies, mainly related to the connection systems. Several collapses occurred because of the failure of the connections between the structural elements: several horizontal elements (e.g. roof elements and beams) experienced significant relative displacements with respect to the supporting ones (e.g. beams and columns), collapsing due to the loss of the support. Some studies have been already performed in order to assess the vulnerability of these structures $[5,6]$ and some papers investigated the seismic response by means of both extensive photographic reports of the recorded damage in the hit region and descriptions of the main features of the analyzed structural typology. In these works, the authors drawn some main conclusions on the seismic safety of precast structures by means of simplified consideration about the seismic demand. For instance, in Magliulo et al. [4] the widespread failure of the friction beam-to-column connections (without mechanical devices, i.e. relying only upon the friction resistance between the connected elements) was justified by comparing the shear resistance of the connection with the elastic spectral accelerations of the first seismic event (May 20 $0^{\text {th }}$ ). Concerning the cladding panels, some similar conclusions were also presented in Belleri et al. [7].

The experience of a seismic event gives also the possibility to develop other investigations: the real response of structural and nonstructural components can be compared to the results of numerical analyses in order to validate the modeling assumptions. The development of both improved analysis methods and models could allow the evaluation of the seismic risk related to precast industrial buildings. Both collapse risk and direct economic losses could be evaluated by means of numerical results, as already provided for RC frame structures [8,9]. Some validation of numerical models were performed in the past and some examples concerned the Emilia-Romagna earthquakes: they investigated the behavior of some structural typologies, as historical constructions [10] and masonry structures $[10,11]$. In these studies the comparison between the numerical results and the recorded damages demonstrated the capability of the proposed models in predicting the seismic response of 
common structural typologies. On the contrary, few similar studies were developed for precast industrial buildings $[12,13]$. In Magliulo et al. [12] the authors assessed the seismic safety of some existing precast RC buildings, typically employed in Europe. The vulnerability of the existing friction beam-to-column connections was demonstrated by means of nonlinear static and dynamic analyses. The adopted models of the precast RC structures did not take into account the friction resistance of the connections: the safety was verified by comparing a posteriori the shear seismic demand on the connections, modelled as pinned, and their friction resistance. In Casotto et al. [13] a seismic fragility model for Italian RC precast buildings was obtained by means of several nonlinear analyses on different buildings typologies. The nonlinear model consisted of columns and beams and the beam-to-column connections were assumed as hinges. The collapse limit state due to the loss of support of the beam was verified a-posteriori by adopting two approaches: 1) the shear demand in at least one column exceeding the connection capacity; 2) the sliding displacement (Newmark sliding block analysis) of the beam exceeding its support length.

It is worth noting that several experimental studies were developed in the last decades in order to define the best models for precast RC structures. For instance, some tests investigated the inelastic behavior of structural elements [14] and some other studies developed models of the connection systems (i.e. designed according to modern building codes), such as between structural elements $[15,16]$ and between structural and nonstructural components [17]. However, these investigations are mainly referred to new buildings, designed for seismic actions according to modern codes. Some investigations were also performed concerning the seismic safety of high-rack structures [18], typically employed in industrial buildings; these elements can influence the seismic response of the whole building and their failure can significantly increase the economic impact of the earthquake due to the contents losses. Concerning existing structures, several work were developed in order to define reliable and efficient retrofitting solutions for elements and connection systems [19, 20].

The presented paper aims at simulating the structural collapse of a precast RC building with friction connections, occurred during the Emilia-Romagna earthquakes in 2012. The damage was recorded during an in-situ survey after the seismic events and both the geometrical features of the structural elements and the mechanical properties of the materials were provided by the original technical reports. The main goal of the paper is the definition of a reliable modeling approach, validated on the actual recorded damage of the structure after the earthquake. The comparison between the analytical results and the actual response of the investigated structure also leads to some considerations about the main causes of the recorded response. 


\section{THE CASE STUDY}

The investigated case study is a precast RC one-story building with friction connections, located in Mirandola (Modena, Italy). This building was hit by two earthquakes, occurred in Emilia-Romagna region on May $20^{\text {th }}$ and $29^{\text {th }}, 2012$. The structure was designed and built in 1990 for industrial and commercial purposes.

Both the geometrical features of the constituting elements and the properties of the structural materials were provided to the authors by the designers. Fig. 1 shows the plan view of the structure, consisting of 6 bays of $20 \mathrm{~m}$ in the $\mathrm{X}$ direction and 5 bays of $10 \mathrm{~m}$ in the $\mathrm{Y}$ direction. In this figure, the labels (A-D) indicate the different typologies of the vertical structural elements (precast columns), described in the following.

The structure consists of an assemblage of precast RC columns, fixed at the base with isolated socket foundations. The total height of the columns is equal to $7.3 \mathrm{~m}$. The structure is closed by $8.9 \mathrm{~m}$ high vertical panels along the perimeter. In the $\mathrm{X}$ direction, the columns are connected at the top by precast prestressed beams (principal beams) with variable cross-section (Fig. 2). In the Y direction, the columns are connected by girders (secondary beams) with U cross-section (Fig. 3). The roof consists of precast elements, supported by the principal beams and spaced out by transparent plastic elements ( 2 for each X-bay, see Fig. 2). The total seismic weight of the structure is equal to about $3.0 \mathrm{kN} / \mathrm{m}^{2}$.

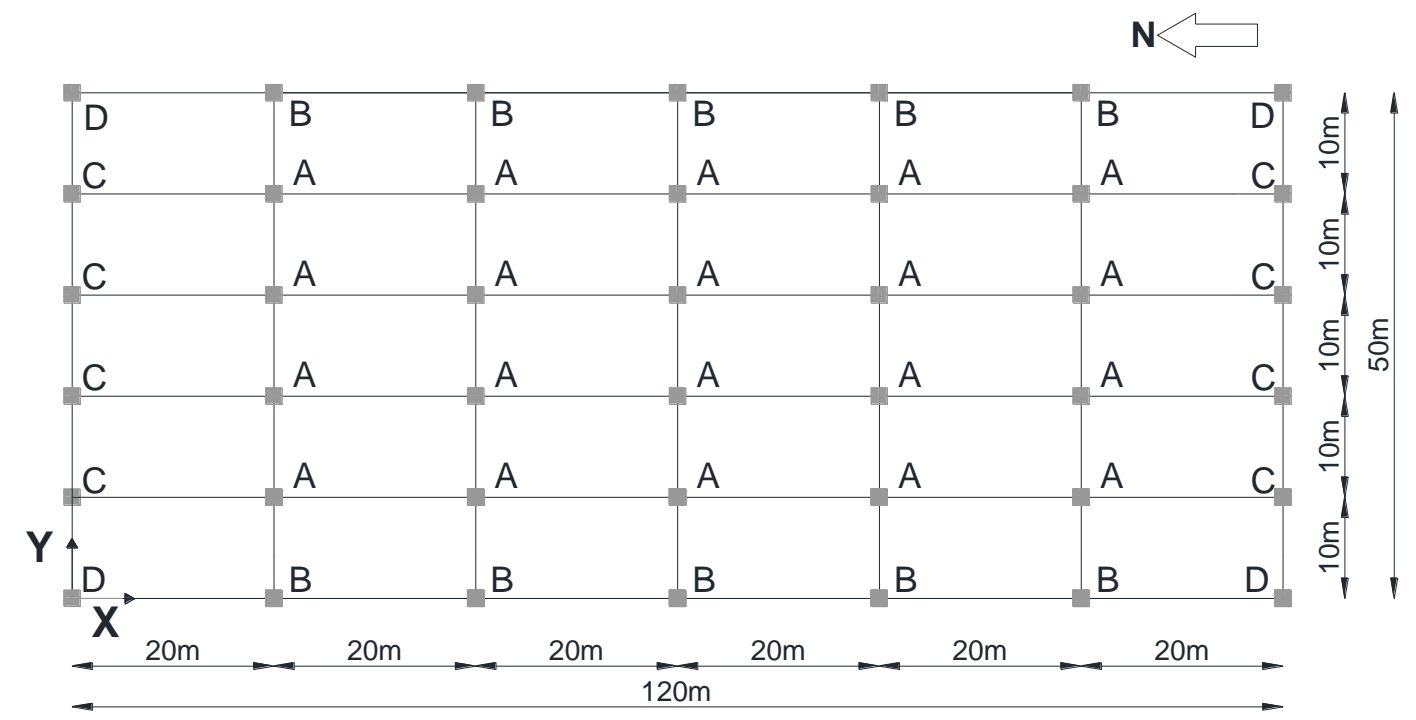

Fig. 1 Plan view of the case study 


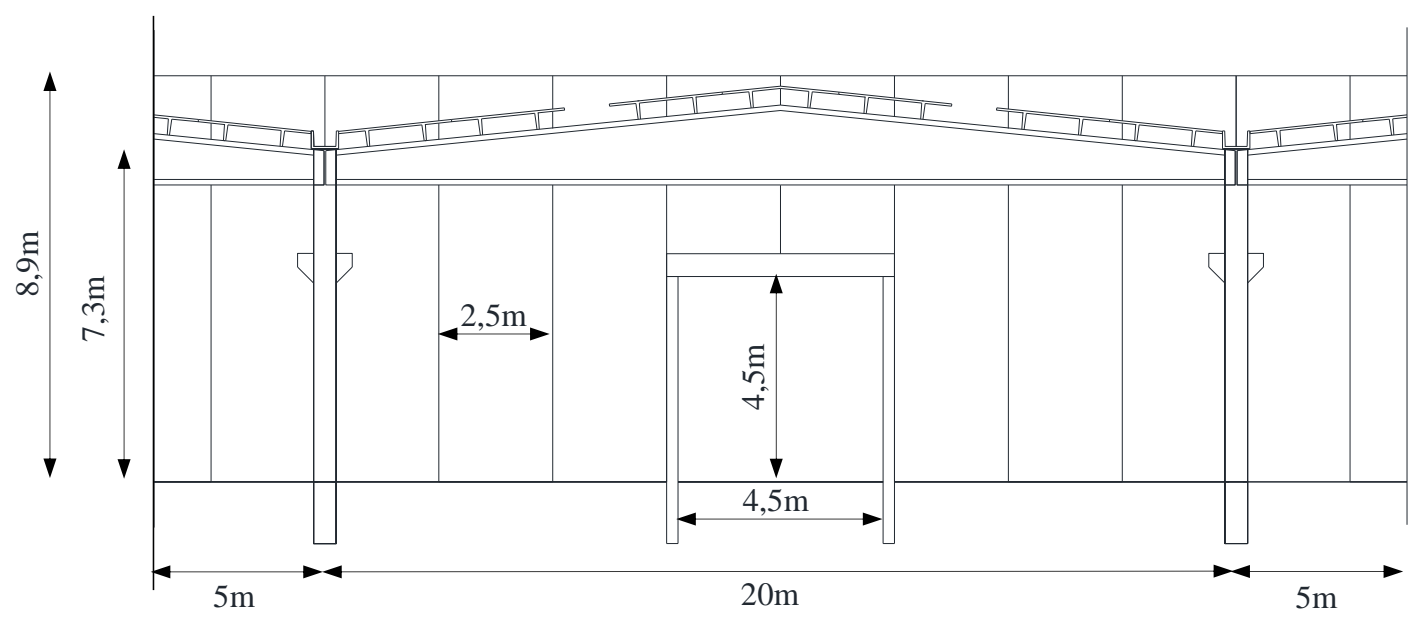

Fig. 2 Frontal inside view of the case study (X direction)

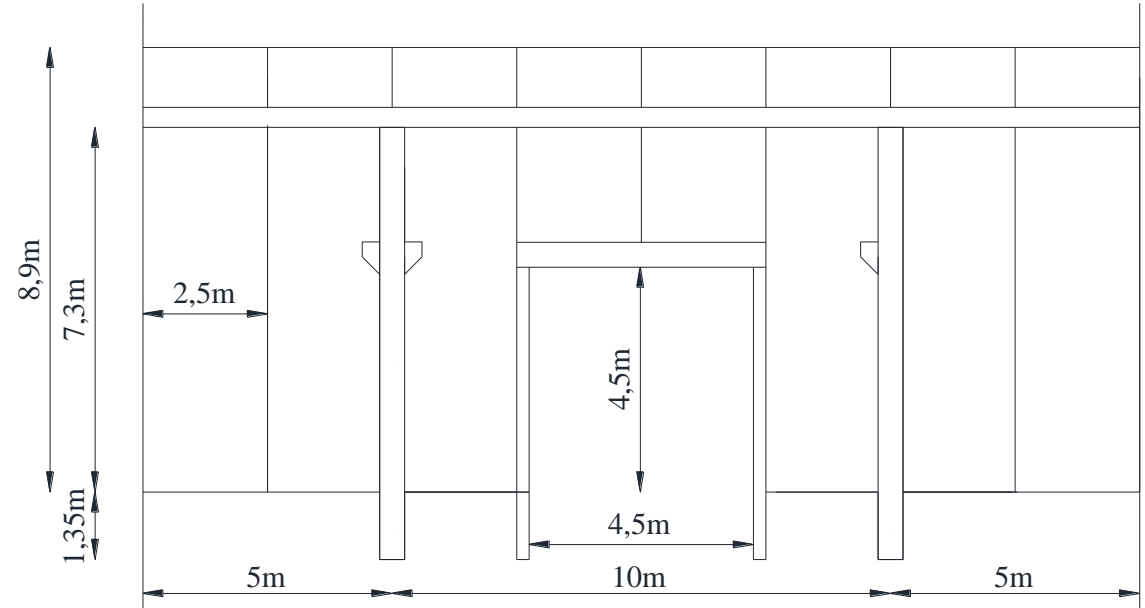

Fig. 3 Lateral inside view of the case study (Y direction)

\subsection{Structural elements}

The principal beams are prestressed elements with a cross-section that varies along its longitudinal axis (global X-axis) in terms of both height and cross-section shape. The beam has a rectangular shaped cross-section at the connection with the column and an I-shaped cross-section at the midspan; the height increases along the $\mathrm{X}$-axis from a minimum value of $75 \mathrm{~cm}$ to a maximum value of $175 \mathrm{~cm}$ (Fig. 2). The secondary beams are U-shaped elements with a base of $60 \mathrm{~cm}$ and a total height of $40 \mathrm{~cm}$. There are two typologies of roof elements in the structure: TT roof elements $(6$ for each $\mathrm{X}$-bay) and $\mathrm{T}$ roof elements ( 2 for each X-bay). The TT elements (in the following called big roof elements) are located close to the columns whereas the $\mathrm{T}$ elements (in the following called small roof elements) are located close to the mid-span of each X-bay (Fig. 2). In this paper, the reinforcement details in beams and roof elements are not reported since these elements can be modelled as elastic elements in the structural model, as described in the following section.

Four different typologies of columns are identified in the structure by taking into account the crosssection dimensions, the longitudinal reinforcement and the applied axial force (see the labels in Fig. 
1). According to the values of the axial load, the columns are distinguished in internal columns (columns A), perimetral columns (columns B and C) and corner columns (columns D).

The features of the columns are summarized in Table 1: B is the column dimension along the global $\mathrm{X}$ direction, $\mathrm{H}$ is the column dimension along the global $\mathrm{Y}$ direction, $\Phi$ and $\rho$ are the diameter and the percentage of longitudinal reinforcement, $\Phi_{\text {stirrups }}$ is the diameter of the stirrups and $s$ is the stirrups spacing. All the rectangular columns are placed with the long side along the $\mathrm{X}$ direction.

The above-described characteristics comply with the building codes in force on the construction year (1990).

For all the structural elements, the adopted concrete has a characteristic cubic compressive strength of 50MPa. The columns are precast elements and the reinforcement steel has a characteristic yielding strength of $440 \mathrm{MPa}$.

Table 1 Cross-sections dimensions and reinforcement details of columns

\begin{tabular}{|c|c|c|c|c|c|c|}
\hline Column & B (along X) & H (along Y) & $\Phi$ & $\rho$ & $\boldsymbol{\Phi}_{\text {stirrups }}$ & $\mathbf{S}$ \\
\hline$[-]$ & {$[\mathrm{cm}]$} & {$[\mathrm{cm}]$} & {$[\mathrm{mm}]$} & [\%] & {$[\mathrm{mm}]$} & {$[\mathrm{cm}]$} \\
\hline $\mathrm{A}$ & 50 & 40 & \multirow{4}{*}{$4 \Phi 18+4 \Phi 16$} & 0.91 & \multirow{4}{*}{6} & \multirow{4}{*}{20} \\
\hline $\mathrm{B}$ & 50 & 50 & & 0.73 & & \\
\hline $\mathrm{C}$ & 50 & 40 & & 0.91 & & \\
\hline $\mathrm{D}$ & 50 & 50 & & 0.73 & & \\
\hline
\end{tabular}

\subsection{Connection systems}

The investigated structure has the typical features of an Italian twenty-century one-story precast RC structure, not designed for seismic actions: the connections between the structural elements (beams, columns and roof elements) are friction connections, i.e. relying only on the friction between the connected elements, without any mechanical device. Indeed, according to the Italian seismic zonation evolution, in 1990 the site of the case study was not included in the seismic-prone zones and, in such a case, the Italian code in force at that time allowed the use of friction connections. The connections between the principal beams and the columns provide only a neoprene pad $(23 \mathrm{~cm} \times 15 \mathrm{~cm} \times 1 \mathrm{~cm})$ between the two concrete elements (Fig. 4). The contact surface has a length of $23 \mathrm{~cm}$ in the $\mathrm{X}$ direction. Friction connections were also provided between the roof elements and the principal beams with a neoprene pad $(7 \mathrm{~cm} \times 5 \mathrm{~cm} \times 1 \mathrm{~cm})$ and a contact surface length of $13 \mathrm{~cm}$ in the Y direction (Fig. 5).

The connection between the girder and the column provides bolted steel angles with a very low rotational strength. In this study, the girder-to-column connections are assumed as hinged, able to avoid the relative displacements between the two connected elements in the Y direction. 


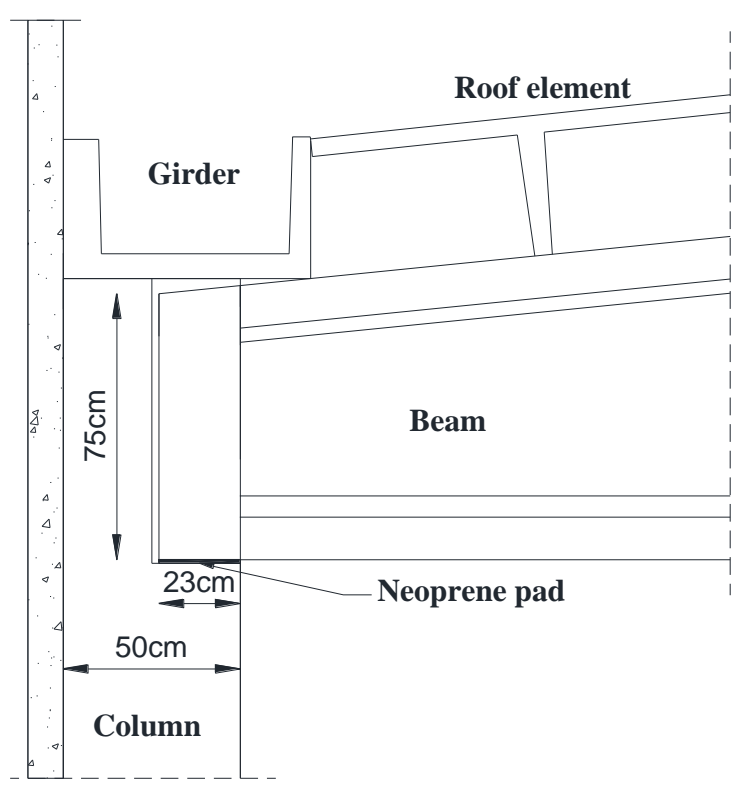

Fig. 4 Layout of the connection between the principal beam and the column

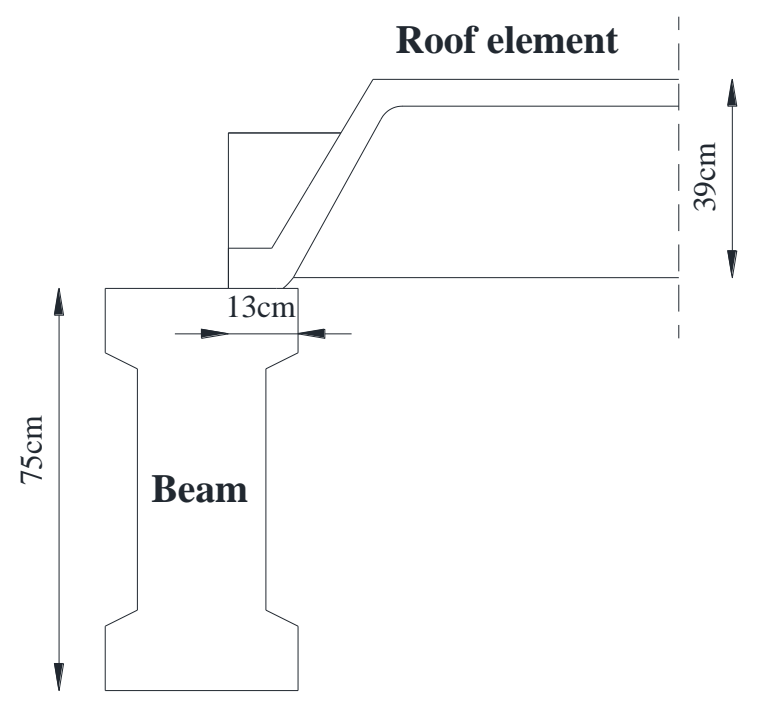

Fig. 5 Layout of the connection between the roof element and the principal beam

\section{DESCRIPTION OF THE OCCURRED DAMAGE}

The investigated building experienced the most serious damages during the seismic event on May $29^{\text {th }}$. An in-situ survey allowed recording the damage in all the elements: vertical structural elements (columns), connection systems and nonstructural panels. Since severe damage occurred, the direct inspection of the internal part of the building was limited. However, both the openings in the structure and the cladding panels collapse allowed the inspection of the building from the outside. At the time of the in-situ inspection, no retrofitting action was performed.

Precast columns experienced significant rotations around the global Y-axis at the base: large cracking and spalling of the concrete demonstrated the attainment of the yielding strength of the RC columns, i.e. either the yielding of the steel bars or the attainment of the ultimate strain in the compressed cover concrete (Fig. 6). The columns damage caused an evident rotation of the structure around the global Y-axis (Fig. 7).

The main damage was recorded in the connections of the horizontal structural elements. The principal beams experienced small relative displacements with respect to the supporting columns (Fig. 8). The amplitude of the experienced displacements did not exceed the contact surface of the beams $(23 \mathrm{~cm})$ : no loss of support phenomena of principal beams occurred in the structure after the two seismic events. On the contrary, the roof elements experienced significant relative displacements (Fig. 9a) and some elements collapsed because of the loss of the support (Fig. 9b). 


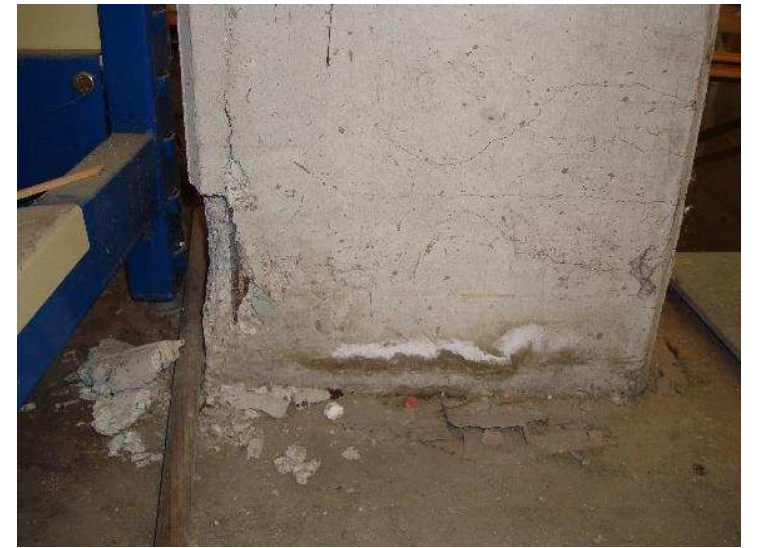

Fig. 6 Damage at the column base after the event on May $2^{\text {th }}$

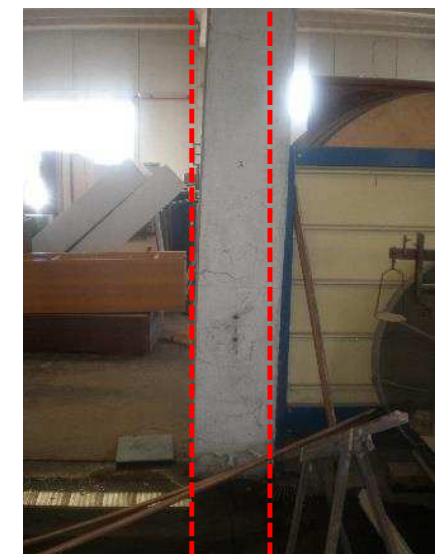

Fig. 7 Rotation of the columns around the global Y direction after the event on May $2^{\text {th }}$

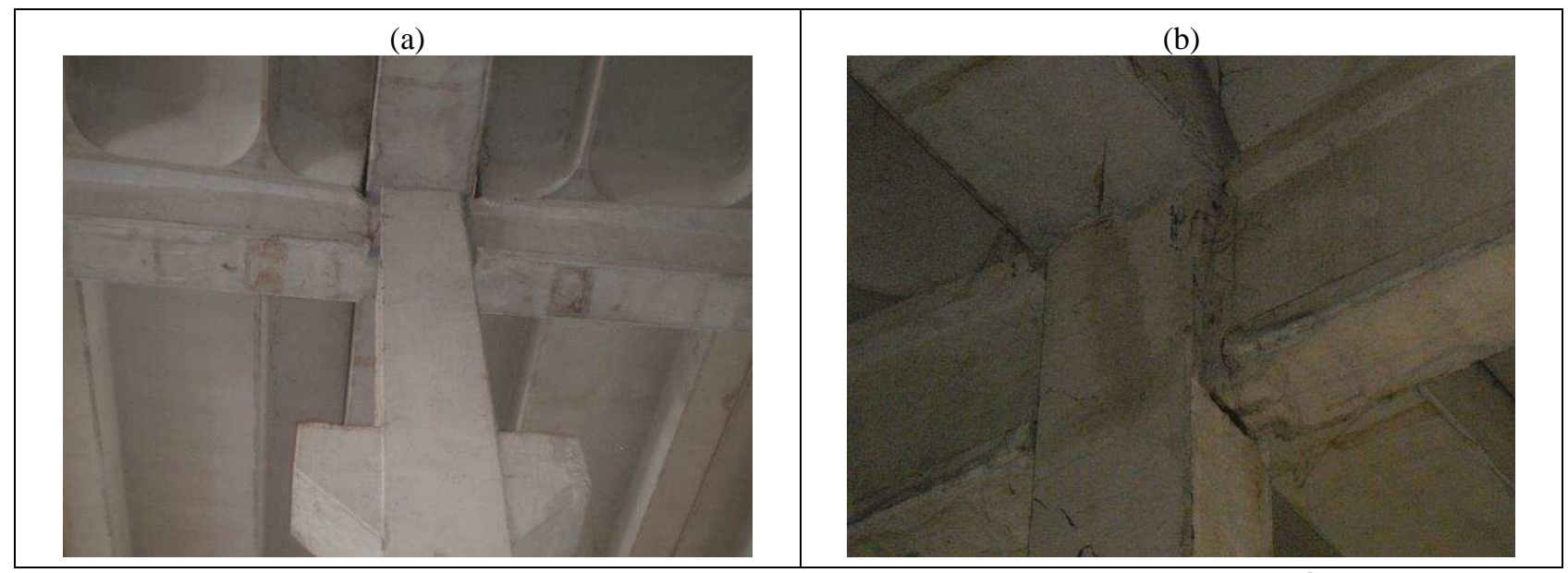

Fig. 8 Damage of the beam-to-column connections after the event on May $2^{\text {th }}$

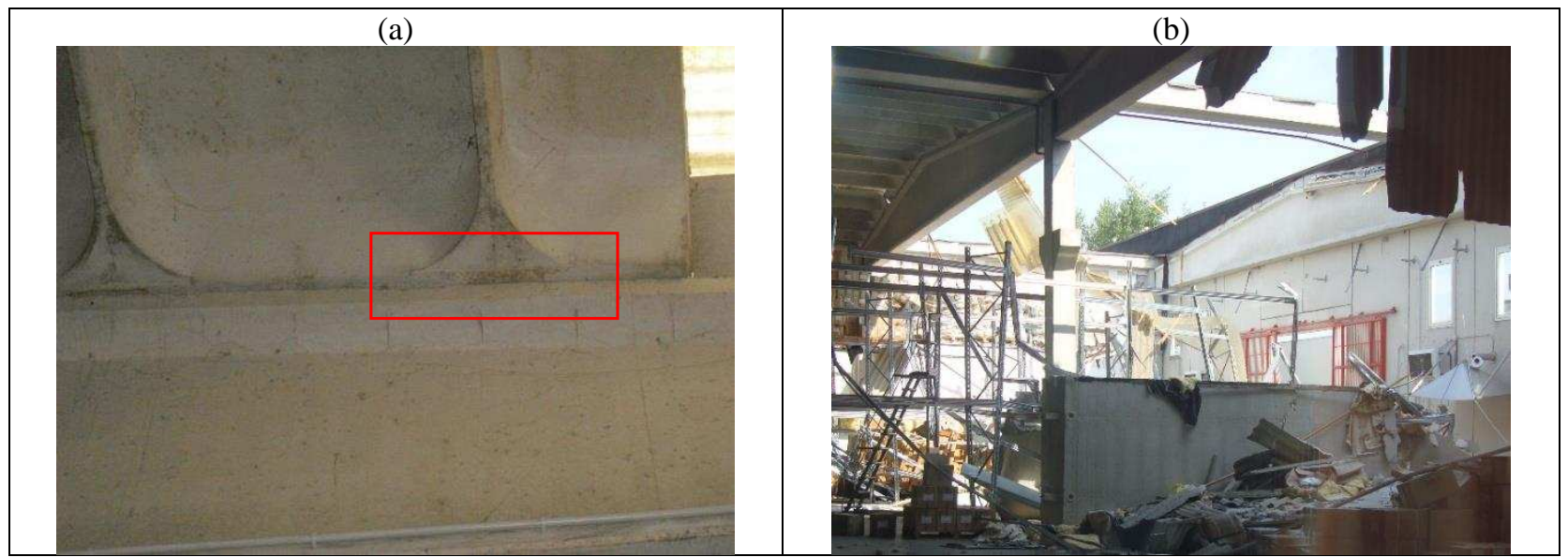

Fig. 9 Damage of the roof-to-beam connections after the event on May $29^{\text {th }}$ : (a) dislocations and (b) loss of support phenomena

\section{NONLINEAR MODEL}

Nonlinear dynamic analyses are performed by OpenSees code [21], with the accelerograms of the two seismic events, recorded close to the case study site.

The nonlinear model provides all the structural elements, according to their real dimensions and location; all the masses are distributed along the structural elements. 
In this study, the influence of the cladding panels is neglected. The panel-to-structure interaction can occur during a seismic event (dynamic action); this interaction can influence the structural response under dynamic actions: the stiffness of the structure can considerably change if the cladding panels interact with the structure. However, if this interaction occurs the panel-to-structure connections fail in the very early stages of the seismic event (corresponding to low acceleration intensities) because they were not designed for such actions. Therefore, the authors assume that the overall structural response of the bare system is representative of the real response during the severe part of the seismic event. This assumption is also justified in the study of this case-study: during the first seismic event, most of the panels either collapsed or experienced large dislocations with respect to the structure because the panel-to-structure connections failed.

\subsection{Model of structural elements and connections}

The dissipative behavior of the structure is concentrated at the base of the precast columns, whereas all the horizontal structural elements (beams, girders and roof elements) are introduced in the model as elastic elements. The stiffness of these elements is assumed equal to the value of the gross sections; such an assumption does not influence the seismic response of the structure because of the structural system. The principal beams are assumed as horizontal elements; i.e. the inclination of these elements is very low and it is neglected in the model.

A lumped plasticity approach is assumed in order to simulate the inelastic response of the columns. The adopted damping ratio in the nonlinear analysis is equal to 5\%; a mass proportional damping model (Rayleigh) is adopted in the model. The moment-rotation envelope of the columns hinges consists of three characteristic points: the cracking, the yielding and the ultimate point. The cracking point (moment and rotation) is defined based on the gross section properties. A fiber analysis of the cross-section provides the yielding moment value, whereas the ultimate moment is defined by considering a very low hardening (1\%) value, assumed only for numerical purposes. The hysteretic rule follows the indications given in Ibarra et al. [22].

The yielding and ultimate rotations are evaluated according to Fardis and Biskinis [23]:

$$
\begin{aligned}
& \theta_{\mathrm{y}}=\varphi_{\mathrm{y}} \cdot \frac{\mathrm{L}_{\mathrm{s}}}{3}+0.00275+\mathrm{a}_{\mathrm{sl}} \cdot \frac{\varepsilon_{\mathrm{y}}}{\left(\mathrm{d}-\mathrm{d}^{\prime}\right)} \cdot \frac{0.2 \cdot \mathrm{d}_{\mathrm{b}} \cdot \mathrm{f}_{\mathrm{y}}}{\sqrt{\mathrm{f}_{\mathrm{c}}}} \\
& \theta_{\mathrm{u}}=0.6 \cdot \mathrm{a}_{\mathrm{st}} \cdot\left(1+0.5 \mathrm{a}_{\mathrm{sl}}\right) \cdot(0.3)^{v} \cdot\left[\frac{\max \left\{\begin{array}{c}
0.01 \\
\omega^{\prime} \\
\max \left\{\begin{array}{c}
0.01 \\
\omega
\end{array}\right.
\end{array} \mathrm{f}_{\mathrm{c}}^{0.175} \cdot\left(\frac{\mathrm{L}_{\mathrm{S}}}{\mathrm{h}}\right)^{0.4} \cdot 25^{\left[\frac{\mathrm{a} \rho_{\mathrm{w}} \mathrm{f}_{\mathrm{yw}}}{\mathrm{f}_{\mathrm{c}}}\right.}\right]}{}\right.
\end{aligned}
$$


All the symbols in Eqs. (1)-(2) are dismissed for the sake of brevity; for their meaning, the authors refer to the reference papers. The mean values of the materials mechanical characteristics, declared in the design documents, are adopted. Table 2 shows the characteristic points of the momentrotation envelopes for the representative columns in the structure. For the columns A the axial load is equal to $500 \mathrm{kN}$, for column $\mathrm{B}$ and $\mathrm{C}$ it is equal to $250 \mathrm{kN}$ and for the corner columns (D) it is equal to $125 \mathrm{kN}$.

Table 2 Characteristic points of the moment-rotation envelopes of the columns around the $X$ and the $Y$ direction

\begin{tabular}{|c|c|c|c|c|c|c|}
\hline Column & Direction & $\mathbf{M}_{\mathbf{c r}}$ & $\mathbf{M}_{\mathbf{y}}$ & $\boldsymbol{\theta}_{\mathbf{c r}}$ & $\boldsymbol{\theta}_{\mathbf{y}}$ & $\boldsymbol{\theta}_{\mathbf{u}}$ \\
\hline$[-]$ & {$[-]$} & {$[-]$} & {$[-]$} & {$[-]$} & {$[-]$} & {$[-]$} \\
\hline \multirow{2}{*}{ A } & Around X & 89 & 244 & 0.00234 & 0.0217 & 0.0977 \\
\cline { 2 - 7 } & Around Y & 111 & 315 & 0.00187 & 0.0198 & 0.0888 \\
\hline \multirow{2}{*}{ B } & $\begin{array}{c}\text { Around } \\
\text { X - Y }\end{array}$ & 100 & 253 & 0.00135 & 0.0195 & 0.0945 \\
\hline \multirow{2}{*}{ C } & Around X & 68 & 198 & 0.00180 & 0.0240 & 0.103 \\
\cline { 2 - 7 } & Around Y & 85 & 253 & 0.00144 & 0.0204 & 0.0934 \\
\hline \multirow{2}{*}{ D } & $\begin{array}{c}\text { Around } \\
\text { X - Y }\end{array}$ & 88 & 220 & 0.00118 & 0.0194 & 0.0964 \\
\hline
\end{tabular}

In order to take into account the real dynamic properties of the structure, all the elements are introduced in the model with their real location, i.e. all the eccentricities between the connections and the elements are considered. Fig. 10 shows the considered eccentricities in the $\mathrm{X}$ direction of the structure. Concerning the beam-to-column connection, two eccentricities are defined as rigid links, simulating the distances between the connection (red circle) of the beam (i.e. the center of the neoprene pad) from the barycenter line of the column (black dotted horizontal links) and from the barycenter line of the beam (black dotted vertical links). Concerning the roof-to-beam connections, Fig. 10 shows two eccentricities, simulating the distances of the connection (red squares) from the beam (black dashed lower vertical link) and from the barycenter of the TT element (black dashed upper vertical link). The girders are connected to the columns (red triangle), considering the height of the column forks (black dash-dot link). Fig. 11 shows the other eccentricities in the Y direction of the connection (red triangle) from the barycenter of the TT element (gray dash-dot upper vertical link) and from the barycenter of the beam (black dash-dot horizontal and lower vertical links).

The connections are defined by "equalDOF" constraints between the two linked elements and the assumed degrees of freedom are reported in Table 3. The translational degree of freedom along the $\mathrm{X}$ direction $\left(\mathrm{U}_{\mathrm{x}}\right)$ between the beam and the column is not constrained: in this direction a model of the friction connection is implemented. Similarly, the translational degree of freedom along the Y direction $\left(\mathrm{U}_{\mathrm{y}}\right)$ is not fixed for the roof-to-beam connections. Concerning the roof-to-beam connection, the translational degree along the global X direction (UX) is restrained because of 
convergence issues of the dynamic analyses. Such an assumption does not compromise the results of the analyses because in this direction the relative motion of the roof elements is limited by the adjacent roof elements and the perimeter beams. Moreover, in both the friction connections, the translational degree of freedom along the $\mathrm{Z}$ direction $\left(\mathrm{U}_{\mathrm{z}}\right)$ is not constrained, in order to evaluate the influence of the vertical components of the earthquakes. Concerning the connection between the secondary beams (girders) and the columns, a hinge is assumed, according to the features of the connection system (see section 2.2).

The assumed model neglects the likely interference between two adjacent beams as well as between the principal beams and the columns that could occur during the seismic excitations.

The first and third periods of vibrations are translational along the $\mathrm{Y}$-axis and $\mathrm{X}$-axis, respectively and the second mode is torsional. The periods of vibration are equal to $1.57 \mathrm{sec}, 1.34 \mathrm{sec}, 1.22 \mathrm{sec}$.

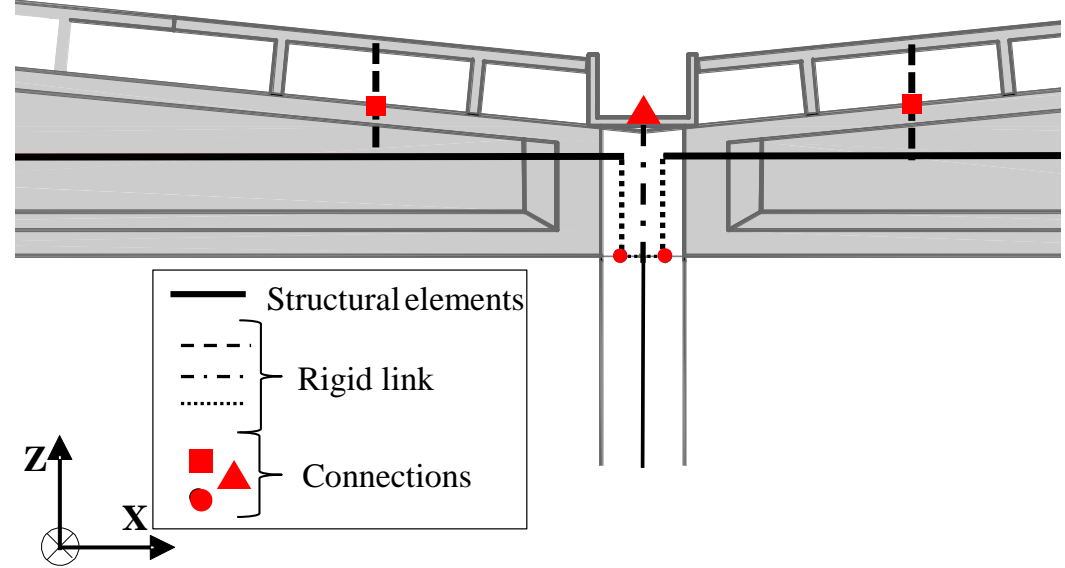

Fig. 10 Structural elements layout and connections position in the $X$ direction

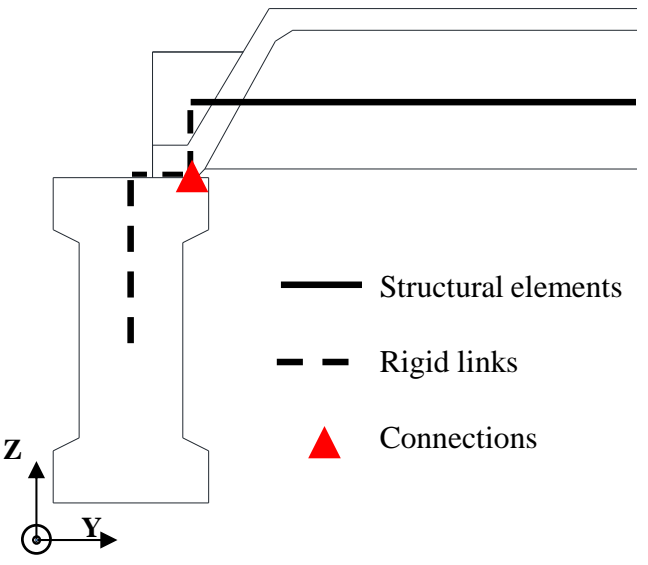

Fig. 11 Structural elements layout and connections position in the $\mathrm{Y}$ direction

Table 3 Constrained degrees of freedom in the connection between the structural elements

\begin{tabular}{c|c|c|c|c|c|c}
\hline \multirow{2}{*}{ Connection } & \multicolumn{7}{|c}{ Constrained degrees of freedom } \\
\cline { 2 - 7 } & $\mathbf{U x}$ & $\mathbf{U y}$ & $\mathbf{U z}$ & $\mathbf{R x}$ & $\mathbf{R y}$ & $\mathbf{R z}$ \\
\hline \hline Beam - column & NO & YES & NO & YES & NO & NO \\
\hline Girder - column & YES & YES & YES & NO & YES & NO \\
\hline Roof - beam & YES & NO & NO & NO & YES & NO \\
\hline
\end{tabular}

\subsection{Frictional connections modeling}

The frictional connections between the structural elements are introduced in the nonlinear model by means of the "Flat slider bearing" element of the OpenSees code library.

This frictional element is defined as an object between two nodes: the i-th node, that represents the flat sliding surface, and the $\mathrm{j}$-th node, that represents the slider. Concerning the beam-to-column 
connection, the sliding surface is the column and the slider is the beam. Concerning the roof-tobeam connection, the sliding surface is the beam and the slider is the roof element.

The adopted frictional element provides the definition of the connection behavior along the different directions:

- compressive/tensile stiffness along the direction of the axial load, i.e. the global Z-axis in this study;

- translational stiffness along the slider horizontal direction; i.e. the global X-axis for beamto-column connections and Y-axis for roof-to-beam connections, in this study;

- $\quad$ rotational stiffness around the vertical axis, i.e. the global Z-axis in this study;

- rotational stiffness around the horizontal axis, orthogonal to the slider direction.

In the direction of the axial load (global Z-axis), the neoprene compressive stiffness is assigned for compressive loads; on the contrary, a free displacement is allowed for tensile vertical loads in order to capture the element uplift.

The Coulomb model is assumed for the frictional behavior of the connection in the slider horizontal direction: the initial elastic stiffness is defined as the shear stiffness of the neoprene pad and the friction coefficient ( $\mu$ ) can be evaluated with the Eqs. (3)-(4), according to Magliulo et al. [24].

$\mu=0.49 \quad$ if $\sigma_{\mathrm{v}}<0.14 \mathrm{MPa}$

$\mu=\mathrm{c}+\beta / \sigma_{\mathrm{v}} \quad$ if $0.14 \leq \sigma_{\mathrm{v}} \leq 5 \mathrm{MPa}$

The coefficients $\beta$ and $c$ are experimentally evaluated [24] and equal to 0.055 and 0.1 , respectively. The normal stress $\left(\sigma_{\mathrm{v}}\right)$ is the ratio between the axial force in the connection and the contact area (neoprene pad area). The beam-to-column connections have a friction coefficient equal to 0.12 and 0.14 for the largest and the lowest axial force, respectively. The roof-to-beam connections have a friction coefficient equal to 0.12 in the case of the big roof elements and 0.13 for the small ones. The rotational stiffness of the beam-to-column connection around the global $\mathrm{Y}$ axis was assumed negligible; i.e. the relative rotations between the connected elements are allowed.

The adopted model allows considering the interaction between the vertical and horizontal components of the accelerations: the frictional strength changes with the axial force due to the vertical accelerations. However, the value of the friction coefficient is constant during the dynamic analysis. The above interaction is presented for a simple structure in order to verify the frictional element (Fig. 14) under the accelerograms (vertical and horizontal components) of the seismic event on May $20^{\text {th }}$. The change of the axial load is presented for a short time period along the changing of the frictional strength (Fig. 15). In this figure, the initial values of both axial load and frictional 
strength are also reported (red dashed lines) in order to underline the variation during the performed nonlinear analyses.

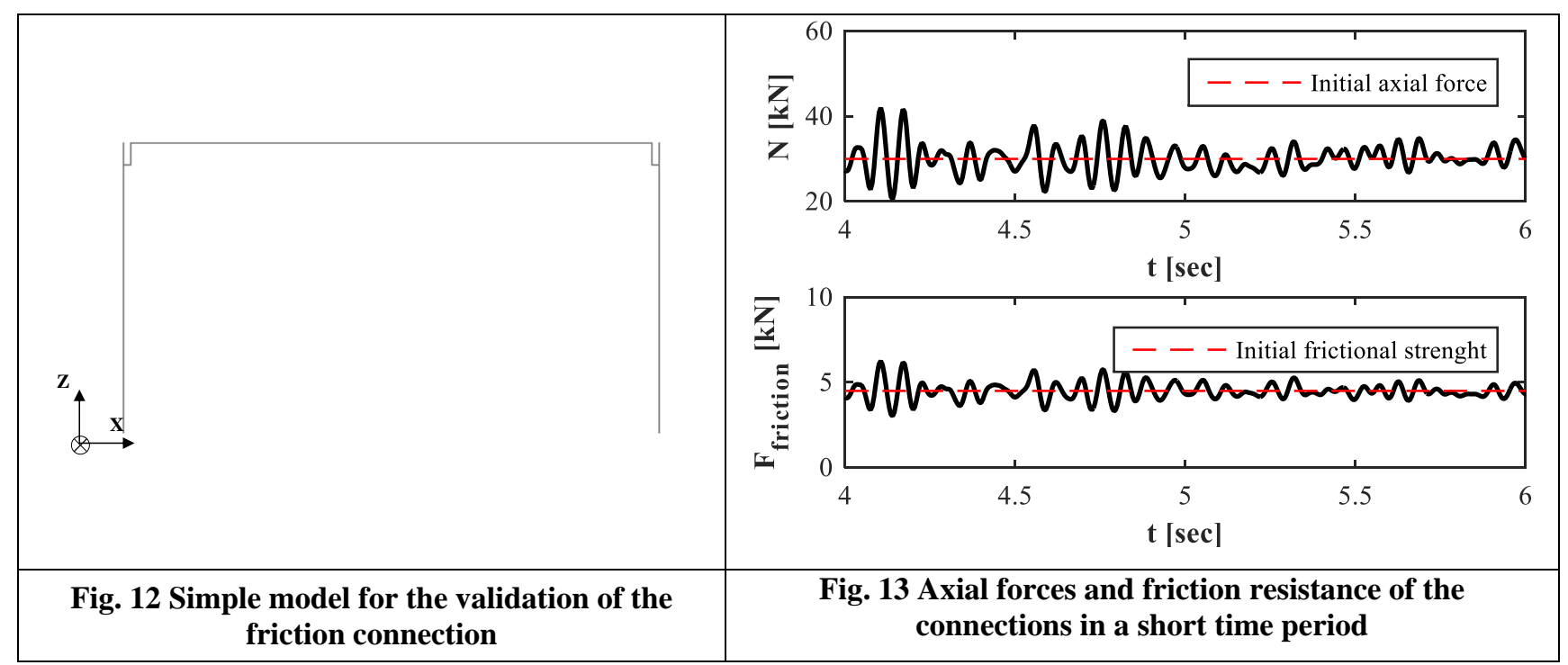

\subsection{Input motion records}

The nonlinear dynamic analyses are performed with the acceleration-time histories recorded by the station MRN (Mirandola, Modena, Italy) of the Italian National Accelerometric Network during the two main events on May 2012. The adopted station is very close to the building site. The considered station is placed on a flat " $\mathrm{C}$ " class soil (shear wave velocity ranging from $180 \mathrm{~m} / \mathrm{s}$ to $360 \mathrm{~m} / \mathrm{s}$ ) according to EC8 [25], as reported in the Italian Accelerometric Archive [26].

The spectra of the horizontal accelerograms of both the events are reported in Fig. 14 (a damping ratio equal to $5 \%$ is assumed). The maximum horizontal accelerations for the first event (May $20^{\text {th }}$ ) are equal to $0.264 \mathrm{~g}(\mathrm{~N}-\mathrm{S}$ component) and $0.261 \mathrm{~g}$ (E-W component) and they are equal to $0.295 \mathrm{~g}$ (N-S component) and $0.224 \mathrm{~g}\left(\mathrm{E}-\mathrm{W}\right.$ component) for the second main earthquake (May $29^{\text {th }}$ ).

The vertical component of a seismic event can influence the response of a precast industrial building. Fig. 15 shows the vertical components of the accelerograms of the two events, recorded at Mirandola station, and Fig. 16 shows the corresponding elastic spectra (a damping ratio equal to 5\% is assumed). It is worth noting the strong vertical motion of the second event, having a peak ground acceleration equal to about $0.9 \mathrm{~g}$. 


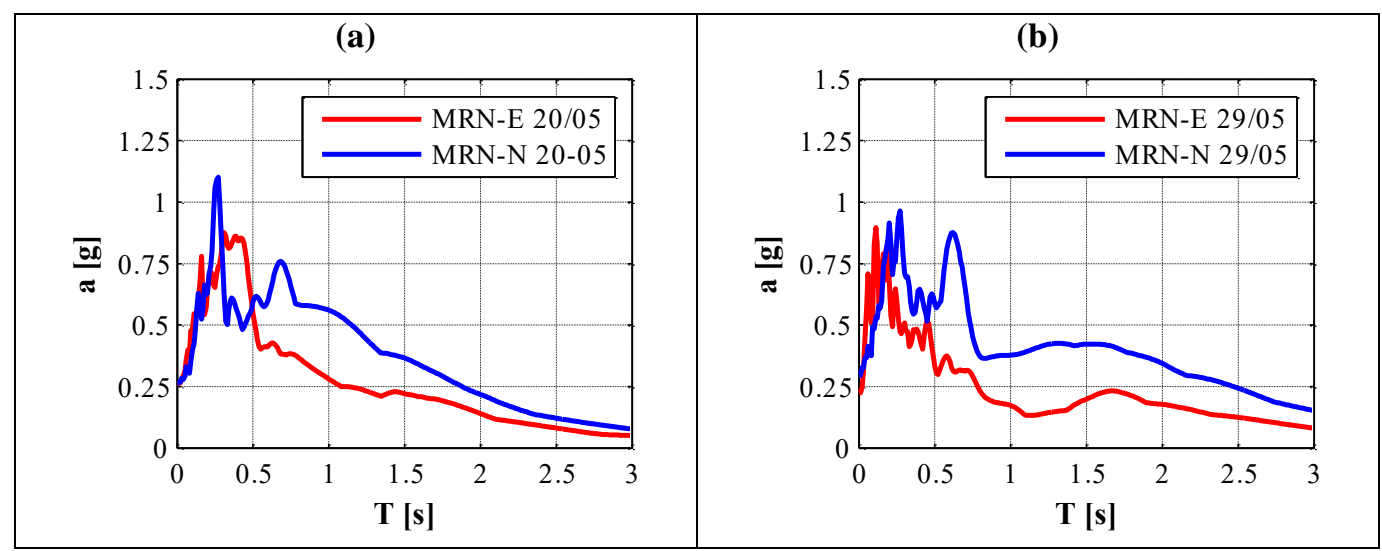

Fig. 14 Elastic response spectra of the accelerograms recorded at Mirandola station: (a) on May $20^{\text {th }}$ and (b) on May $29^{\text {th }}$. A damping ratio equal to $5 \%$ is assumed

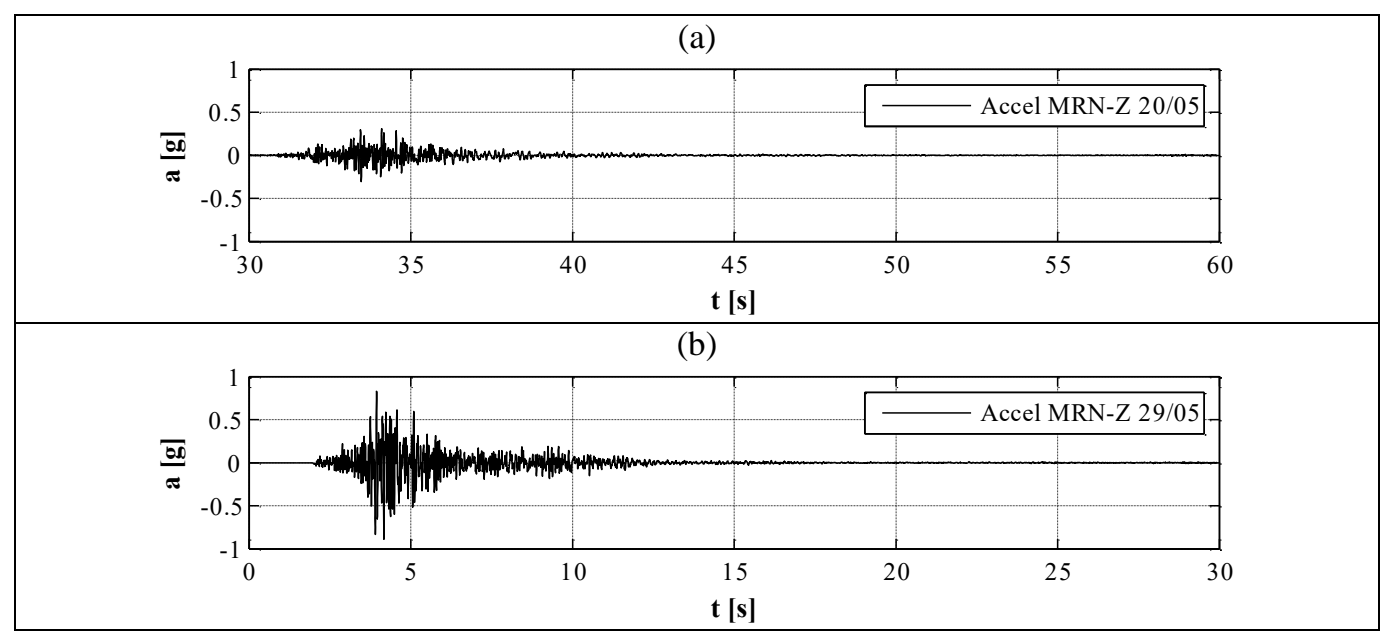

Fig. 15 Vertical component of the accelerograms recorded at Mirandola station: (a) on May $20^{\text {th }}$ and (b) on May $29^{\text {th }}$

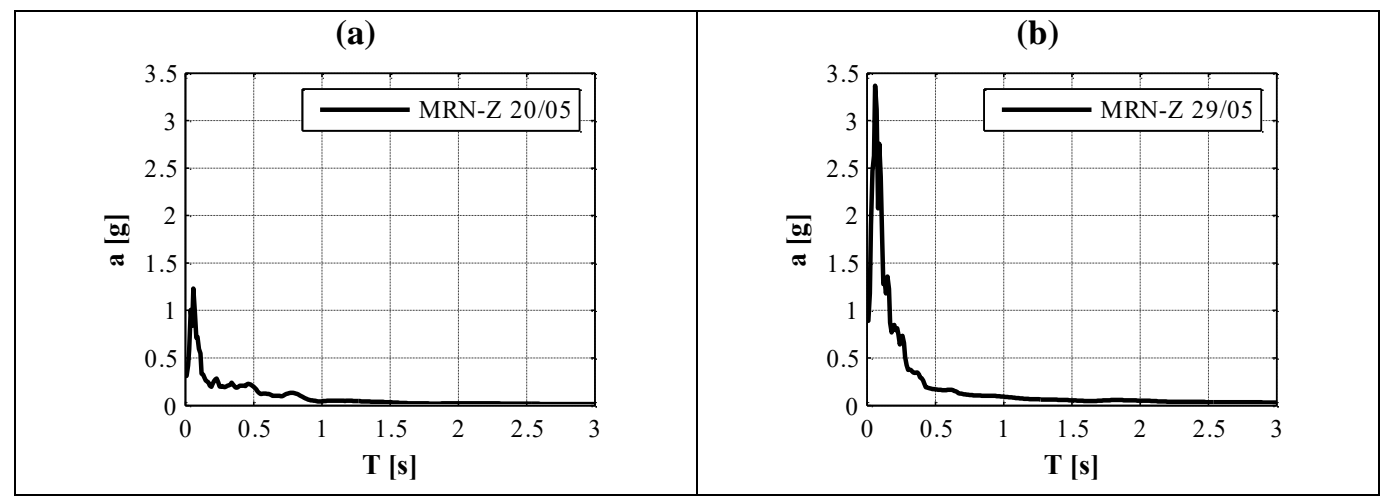

Fig. 16 Elastic response spectra of the accelerograms vertical component recorded at Mirandola station: (a) on May $20^{\text {th }}$ and (b) on May $29^{\text {th }}$. A damping ratio equal to $5 \%$ is assumed

\section{RESULTS OF DYNAMIC ANALYSES}

This section presents the results of the nonlinear dynamic analyses on the above-described structural model. The three components of the two seismic events reported in Section 4.3 are used as input for these analyses. 


\subsection{Columns damage}

Fig. 17 and Fig. 18 show the moment-rotation curves of the plastic hinges at the columns base, obtained under the three components of the May $29^{\text {th }}$ event. The results confirm the field observation: visible rotations occurred in the columns around the global Y direction during the May $29^{\text {th }}$ event. It is worth noting that the columns rotation are slightly larger than the yielding limit value; however, the large yielding rotations of precast slender columns (around 2\%) justifies the recorded drift. This result also agrees with the observed structural response, which did not show a global collapse due to large column rotations.

The shear safety of the columns is also evaluated: the shear resistance, evaluated according to EC8 [27], is always larger than the maximum shear demand along both the horizontal directions.

The occurrence of two consecutive severe seismic events at the same site can cause more severe damage due to the cumulative effect. In the investigated case study, if both the events are considered in the nonlinear analysis, the column behavior does not significantly change, since during the first event the columns do not experience any inelastic excursions. These results are not reported in this paper for the sake of brevity.

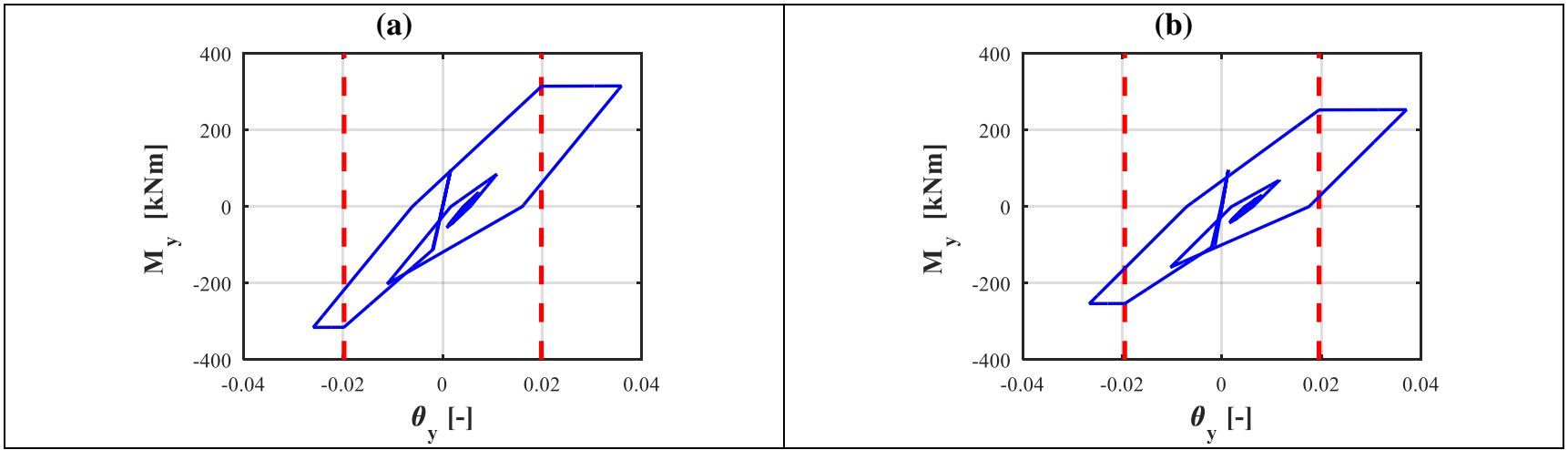

Fig. 17 Moment-rotation envelopes around the $Y$ direction under the three components of the earthquake on May 29 ${ }^{\text {th }}$ (a) column A and (b) column B

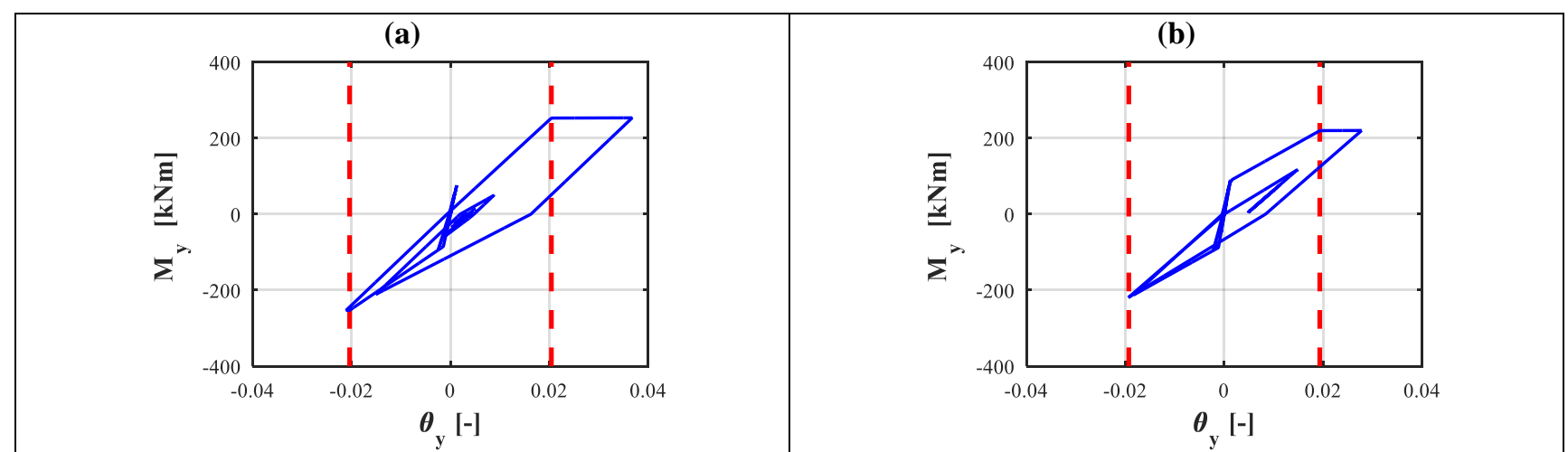

Fig. 18 Moment-rotation envelopes around the $\mathrm{Y}$ direction under the three components of the earthquake on May 29 ${ }^{\text {th }}$ (a) column C and (b) column D 


\subsection{Damage of the roof-to-beam connections}

In this section, the seismic performance of the roof-to-beam connections is investigated by studying the results of nonlinear dynamic analyses performed with the records of both seismic events.

Fig. 19 shows the roof-to-beam relative displacements along the global Y direction (i.e. the longitudinal direction of the roof elements) under the three components of the second earthquake (May 29th): each bar of the histogram corresponds to one roof connection and its height represents the relative displacement amplitude. The limit of the Y-axis displacement is assumed equal to the width of the supporting base of the investigated connection $(13 \mathrm{~cm})$; the attainment of this limit means that the collapse due to the loss of the support occurs. The bars color underlines the amplitude of the connections relative displacements: the darkest color corresponds to the unseating cases. According to these results, during the second event occurred in Emilia-Romagna, many roof elements experienced dislocations and some elements lost their support. This evidence agrees with the real response of the roof elements. This damage can be justified by the strong seismic action in the vertical direction recorded during this event. Such an excitation significantly decreased the frictional resistance of the connections, as demonstrated by the many elements experiencing uplift phenomena in the nonlinear analysis.

If the dynamic analysis is performed with the accelerograms of the first earthquake (May $20^{\text {th }}$ ), small relative displacements (about $2 \mathrm{~cm}$ ) between the roof elements and the principal beams are recorded. Fig. 20 shows the relative displacements between the roof elements and the beam for all the connections in the structure: the limit of the $\mathrm{Y}$-axis is assumed equal to the width of the supporting base of the investigated connection $(13 \mathrm{~cm})$ in order to underline the very small values of the recorded displacements. This evidence still agrees with the real behavior of the structure. Moreover, this result also justifies the choice of neglecting the sequence of the two events in the seismic assessment of the connections: the permanent roof-to-beam displacements after the first event did not influence the distribution of the collapsed elements in the structure during the second seismic event. 


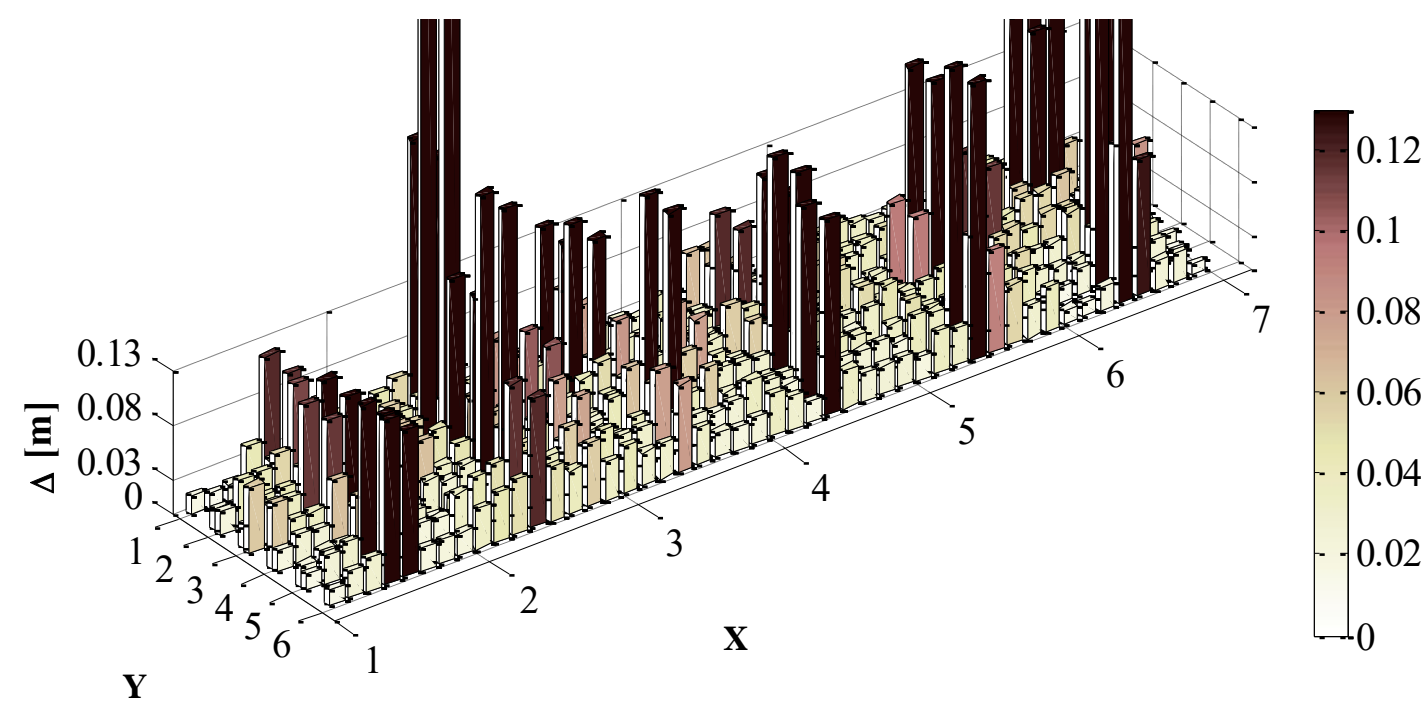

Fig. 19 Relative displacements (height of the bars) at the roof-to-beam frictional connections under the three components of the earthquake on May $29^{\text {th }}$ along the global Y direction

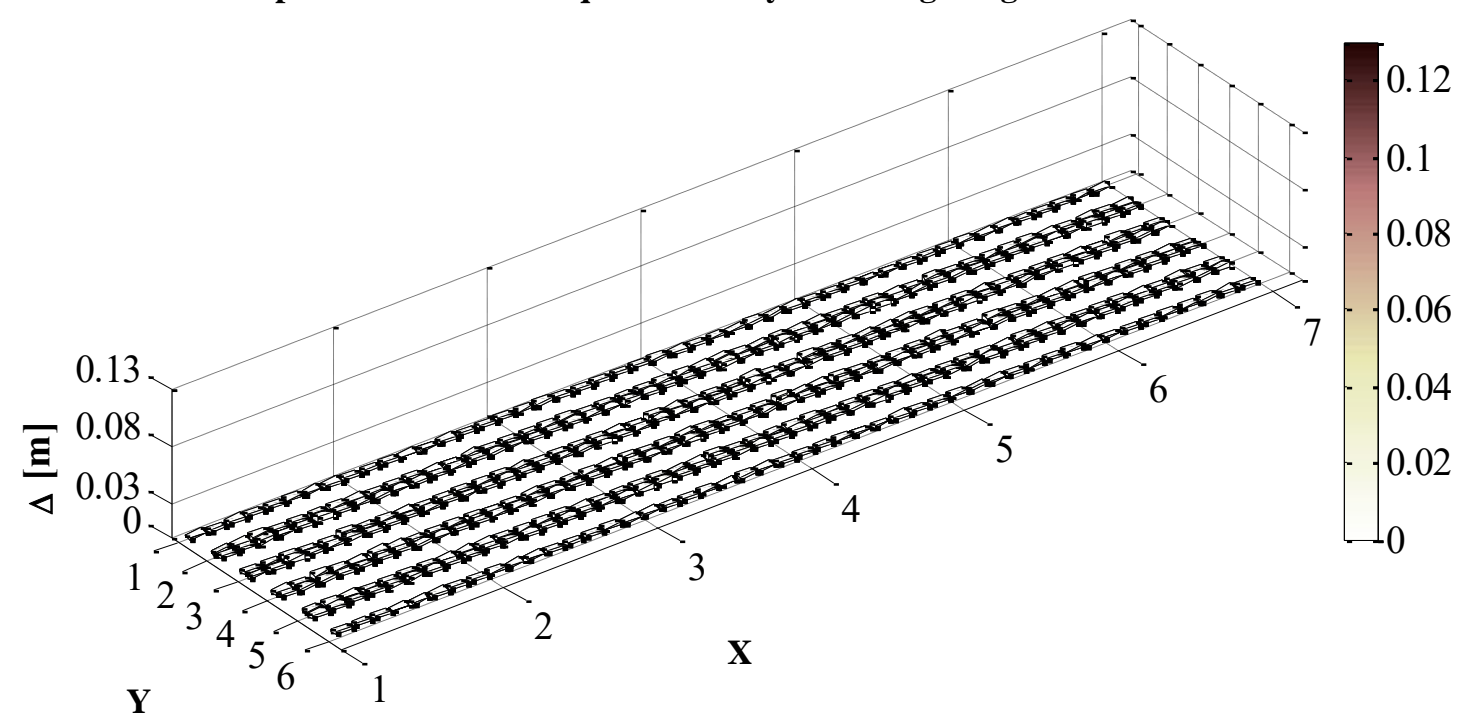

Fig. 20 Relative displacements (height of the bars) at the roof-to-beam frictional connections under the three components of the May $20^{\text {th }}$ earthquake

The largest roof-to-beam displacements are generally recorded for the small roof elements, i.e. the central elements of the X-bays. Both the seismic mass and the stiffness of these roof elements are smaller than the mass and the stiffness of the big TT roof elements; therefore, the vibrational periods of the vertical modes of the two roof typologies do not significantly differ. Moreover, a lower seismic mass reduces both seismic demand (inertia forces) on the element and frictional resistance (axial load) of the connection; therefore, the seismic response does not depend on this parameter. According to these considerations, a similar response could be expected by the two typologies of roof elements. However, the worse response of the small roof elements can be justified by observing that these elements are connected to the mid-span of the principal beam, which experienced larger vertical vibrations than the portion of the beam close to the columns. This phenomenon caused larger vertical accelerations for the roof elements and, then, in some time 
instants, lower friction resistance. This consideration can be supported by the numerical results shown in Table 4, reporting the vertical accelerations, due to the May $29^{\text {th }}$ records, obtained during the analysis for both central and external elements. These values are referred to the right edge of the roof elements in the first X-bay of the structure.

Few big TT elements also experienced significant dislocations, such as the roof elements in the central bays along the Y direction. In this case, the histogram (Fig. 19) shows an unsymmetrical layout of the roof-to-beam relative displacements throughout the structure. This distribution can be justified by different factors, beyond the features of the single elements (e.g. resistance, mass and stiffness). Among the others, the main influencing factors are the column deformation (drift and base rotation), the beam-to-column connection response (i.e. the possible attainment of the frictional resistance) and the location of each roof-to-beam connection. Moreover, the achievement of the frictional resistance in one connection causes the redistribution of the seismic demand in the structure as well as the change of the building dynamic properties.

The results of the dynamic analyses validate the reliability of the adopted friction roof-to-beam connection, in terms of both achievement of the friction resistance and dislocation. However, the matching between the distribution of the recorded roof-to-beam displacements obtained by the analysis and the real location of the loss of support cases is not perfect. Even if the main seismic behavior of the roof elements is gained, some of the failed roof elements do not exhibit collapse during the numerical analysis. For instance, Fig. 10 shows that the roof elements of an entire X-bay failed during the second seismic event while the analysis results do not provide such damage in any bay of the structure. Such a matching is not achieved since the loss of support is verified a posteriori. Indeed, in the real case, the collapse of a TT element causes the redistribution of the seismic demand in the structure as well as the likely collapse of other elements. Future studies will investigate the performance of the structure by employing the elements collapse simulation during the analysis; this could be done by the "collapse removal" command in OpenSees code.

Table 4 Absolute acceleration in the roof elements edges under the three components of the earthquake on May $29^{\text {th }}$ : the distance is the progressive distance between the element barycenter and the origin of the global axes (see Figure 1)

\begin{tabular}{|c|c|c|c|c|c|c|c|c|c|}
\hline \multirow{4}{*}{ 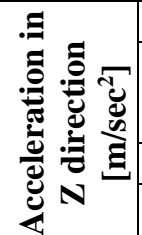 } & Element & 1 & 2 & 3 & 4 & 5 & 6 & 7 & 8 \\
\hline & $\begin{array}{c}\text { Distance } \\
\text { X [m] }\end{array}$ & 1.69 & 4.18 & 7.50 & 9.37 & 10.62 & 12.49 & 15.81 & 18.30 \\
\hline & Max & 2.21 & 2.88 & 3.55 & 20.01 & 11.35 & 4.14 & 3.38 & 2.03 \\
\hline & Min & -2.31 & -3.07 & -3.80 & -19.60 & -11.56 & -4.15 & -3.59 & -2.39 \\
\hline
\end{tabular}

\subsection{Damage of the beam-to-column connections}

The force-displacements envelopes of the friction elements can describe the response of the beamto-column connections. In these envelopes, the deformation is the relative displacement between the 
beam and the column and the force is the shear force in the connection in the $\mathrm{X}$ direction (i.e. the longitudinal direction of the principal beams). Fig. 21a shows the envelopes for columns type A, obtained by the dynamic analysis with the records of the second event (May 29 ${ }^{\text {th }}$ ). The results agree with the experienced damage: the beam experienced relative displacements with respect to the column; however, these displacements never achieved the width of the supporting base $(23 \mathrm{~cm})$. The numerical results justify the absence of unseating phenomena of the principal beams.

Fig. $21 \mathrm{~b}$ shows the force-displacements envelopes of the connections for the column type A, obtained by the dynamic analysis performed with the records of the first event (May $20^{\text {th }}$ ). For these seismic excitations, the relative displacements are very small. Even the sum of the permanent displacements of the first event and the displacements of the second event does not provide the collapse of the beams: the sequence of the two events can be neglected.

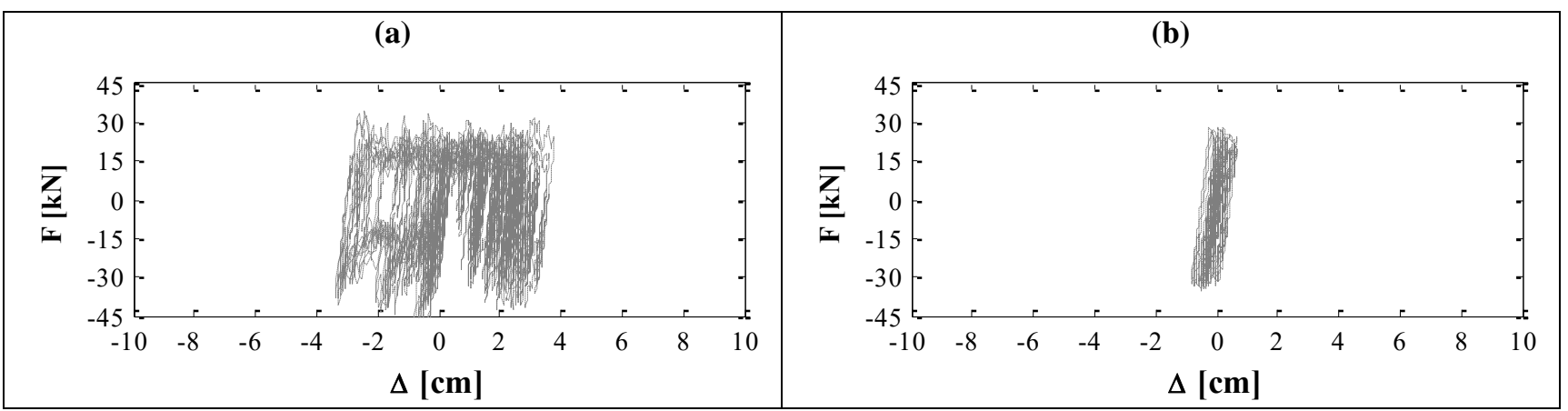

Fig. 21 Force-deformation envelopes of the beam-to-column frictional connections (columns A) under (a) the records of the earthquake on May $29^{\text {th }}$ and (b) the records of the earthquake on May $20^{\text {th }}$

\section{INFLUENCE OF THE VERTICAL COMPONENT}

In order to identify the main cause of the building collapse, a dynamic analysis is performed with only the horizontal components of the second seismic event. Fig. 22 shows the relative displacements of the roof-to-beam connections and Fig. 23 shows the force-displacement curve of the beam-to-column connections. In this case, no elements experienced significant relative displacements. Concerning the roof, the displacement in the friction connections is always smaller than $5 \mathrm{~cm}$ and the distribution of the seismic demand on the roof elements is quite constant in the whole structure, as demonstrated by both the height and the color of the bar in the figure.

It can be stated that the vertical component of the earthquake of May $29^{\text {th }}$ is the main cause of the observed unseating phenomena of the case study. This evidence agrees with other research studies on other structural typologies, damaged during the Emilia-Romagna seismic events [28]. The numerical results can be confirmed by the recorded spectral accelerations during the two main seismic events at low periods (periods of the horizontal elements): during the second event (May 29th), the vertical spectral accelerations are larger than the values recorded during the first seismic 
event. By adopting the vibration periods of the vertical modes for both external and internal principal beams $(0.35 \mathrm{sec}$ and $0.28 \mathrm{sec}$, respectively), the vertical spectral accelerations are equal to $0.19 \mathrm{~g}$ or equal to $0.47 \mathrm{~g}$ if the first or the second seismic event is considered, respectively. In the case of the roof elements, the maximum vertical spectral accelerations are equal to $0.22 \mathrm{~g}$ or equal to $0.81 \mathrm{~g}$ if the first or the second seismic event is considered, respectively. These accelerations are evaluated by considering the following assumptions.

- The periods of the roof elements are calculated by modal analysis; these values are also verified by analytically evaluating the vertical modes for a simply supported beam (the roof element) with distributed mass. The evaluated periods vary between $0.2 \mathrm{sec}$ and $0.27 \mathrm{sec}$.

- The accelerations are evaluated as the spectrum values at the periods of the roof elements. The adopted spectra are evaluated from the ground motions of the two seismic events.

This simplified method is approximate since the accelerations of the roof elements should be evaluated by considering the response of the principal beams. However, the comparison between the amplitudes of the accelerations still demonstrates the much larger damage of the connection systems in the case of the second event. This comparison also justifies the worse response of the roof elements with respect to the principal beams.

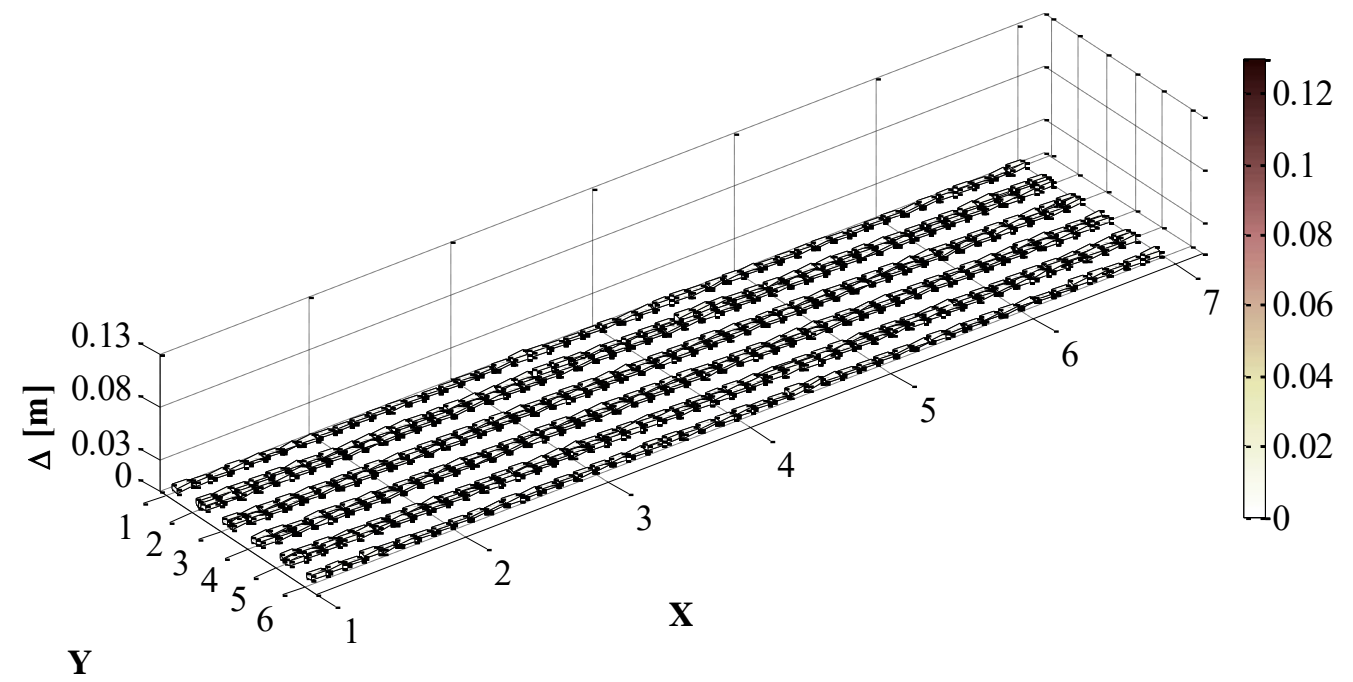

Fig. 22 Relative displacements (height of the bars) at the roof-to-beam frictional connections under the two horizontal components of the earthquake on May $29^{\text {th }}$ 


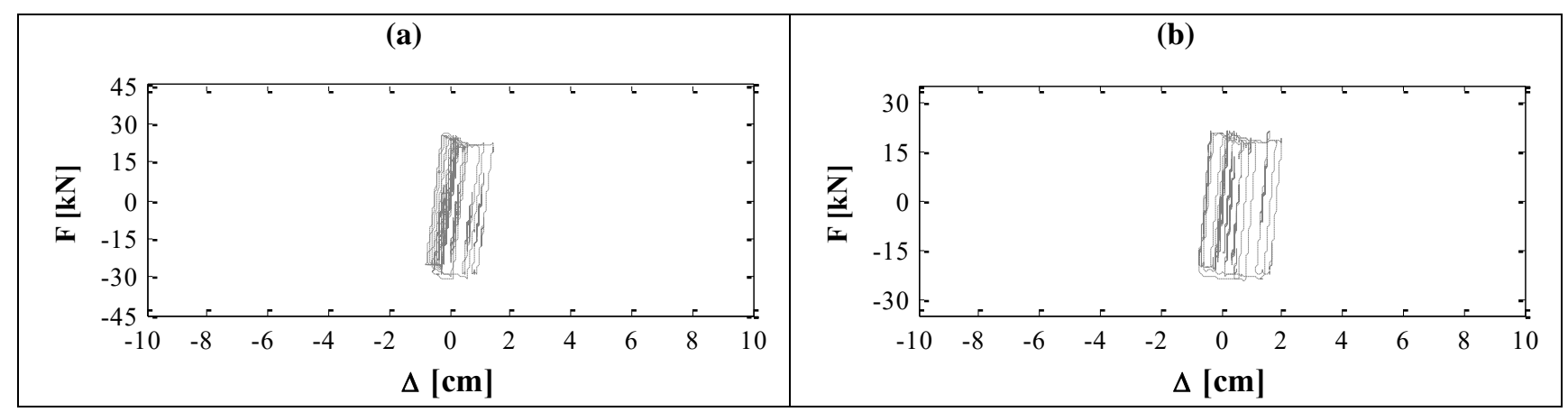

Fig. 23 Force-deformation envelopes of the beam-to-column frictional connections under the horizontal components of the earthquake on May $29^{\text {th }}$ : (a) columns A and (b) columns B

\section{CONCLUSIONS}

The paper deals with the seismic assessment of a precast RC one-story building with friction connections, located in the epicentral area of the Emilia-Romagna earthquakes. The industrial structure experienced severe damage after the May $29^{\text {th }}$ event. A direct inspection after the seismic event showed that the most serious damages were:

- high rotations and yielding at the base of the vertical structural elements;

- relative displacements between the beams and the columns;

- significant dislocations between the roof elements and the beams, with some cases of loss of support.

The main goals of this study are both the validation of the structural model and the justification of the recorded damage after the earthquakes by means of nonlinear dynamic analyses. The nonlinear structural model provides all the structural elements; the influence of the cladding panels on the overall structural seismic behavior is neglected because of the proved low strength of the panel-tostructure connections. The adopted model for the frictional connections allows considering the interaction between the vertical and horizontal components of the accelerations; however, the value of the friction coefficient remains constant during the dynamic analysis.

The dynamic analyses demonstrated the capability of the model in simulating the real response of the structure. The results confirmed that the most of the damage was caused by the second seismic event and the numerical evidences agreed with the real recorded damage:

- at the columns base, the plastic hinges experienced inelastic rotations and the absence of shear failures in these elements is also confirmed;

- the adopted frictional element was able to simulate the behavior of both the beam-to-column connections and the roof-to-beam connections;

- the amplitudes of the relative displacements at the roof-to-beam connections justified the unseating phenomena for the roof elements. 
It is worth underlining that the recorded failures of the roof elements in the analysis do not perfectly match the real loss of support cases. This limit of the study might be overcome by simulating the elements collapse during the analysis.

The main damage was related to the collapse of the roof elements. In order to justify these failures, one nonlinear dynamic analysis is also performed without considering the vertical component of the second seismic event. The results of this analysis confirmed that the significant vertical action caused very large relative displacements due to the reduction of the frictional resistance, related to uplift phenomena. The vertical accelerations in the roof-to-beam connections were larger than the values in the beam-to-column connections; this outcome justified the different behavior of the two horizontal elements.

\section{REFERENCES}

[1] Saatcioglu M, Mitchell D, Tinawi R, Gardner NJ, Gillies AG, Ghobarah A, Anderson DL, Lau D. The August 17, 1999, Kocaeli (Turkey) earthquake - damage to structures. Can J Civil Eng. 2001;28:715-737.

[2] Toniolo G, Colombo A. Precast concrete structures: the lessons learned from the L'Aquila earthquake. Struct Concrete. 2012;13:73-83.

[3] Faggiano B, Iervolino I, Magliulo G, Manfredi G, Vanzi I. Post-event analysis of industrial structures behavior during L'Aquila earthquake. Progettazione sismica 2009;3:203-208.

[4] Magliulo G, Ercolino M, Petrone C, Coppola O, Manfredi G. The Emilia Earthquake: Seismic Performance of Precast Reinforced Concrete Buildings. Earthq Spectra. 2014;30:891-912.

[5] Psycharis J, Mouzakis H, Carydis P. Experimental investigation of the seismic behaviour of prefabricated RC structures. Proceeding of the 2nd International Conference, Fib, Naples. 2006.

[6] Toniolo G. Safecast Project: European Research on Seismic Behaviour of the Connections of Precast Structures. COMPDYN 2013 4th ECCOMAS Thematic Conference on Computational Methods in Structural Dynamics and Earthquake Engineering, Kos Island, Greece, 12-14 June 2013. 2013.

[7] Belleri A, Brunesi E, Nascimbene R, Pagani M, Riva P. Seismic Performance of Precast Industrial Facilities Following Major Earthquakes in the Italian Territory. Journal of Performance of Constructed Facilities. 2014;0:04014135.

[8] Mitrani-Reiser J, Beck J. Incorporating Losses Due to Repair Costs, Downtime and Fatalities in Probabilistic-Based Earthquake Engineering. Proceedings, Computational Methods in Structural Dynamics and Earthquake Engineering Crete, Greece. 2007.

[9] Ramirez CM, Liel AB, Mitrani-Reiser J, Haselton CB, Spear AD, Steiner J, Deierlein GG, Miranda E. Expected earthquake damage and repair costs in reinforced concrete frame buildings. Earthq Eng Struct Dyn. 2012;41:1455-1475.

[10] Milani G, Valente M. Comparative pushover and limit analyses on seven masonry churches damaged by the 2012 Emilia-Romagna (Italy) seismic events: Possibilities of non-linear finite elements compared with pre-assigned failure mechanisms. Engineering Failure Analysis. 2015;47:129-161.

[11] Artioli E, Battaglia R, Tralli A. Effects of May 2012 Emilia earthquake on industrial buildings of early ' 900 on the Po river line. Eng Struct. 2013;56:1220-1233.

[12] Magliulo G, Fabbrocino G, Manfredi G. Seismic assessment of existing precast industrial buildings using static and dynamic nonlinear analyses. Engineering Structures. 2008;30:2580-2588. 
[13] Casotto C, Silva V, Crowley H, Nascimbene R, Pinho R. Seismic fragility of Italian RC precast industrial structures. Engineering Structures. 2015;94:122-136.

[14] Fischinger M, Kramar M, Isaković T. Cyclic response of slender RC columns typical of precast industrial buildings. B Earthq Eng. 2008;6:519-534.

[15] Kremmyda G, Fahjan Y, Tsoukantas S. Nonlinear FE analysis of precast RC pinned beam-tocolumn connections under monotonic and cyclic shear loading. B Earthq Eng. 2014;12:1615-1638.

[16] Magliulo G, Ercolino M, Cimmino M, Capozzi V, Manfredi G. FEM analysis of the strength of RC beam-to-column dowel connections under monotonic actions. Constr Build Mater. 2014;69:271-284.

[17] Biondini F, Dal Lago B, Toniolo G. Role of wall panel connections on the seismic performance of precast structures. B Earthq Eng. 2013;11:1061-1081.

[18] Petrovcic S, Kilar V. Effects of Horizontal and Vertical Mass-Asymmetric Distributions on the Seismic Response of a High-Rack Steel Structure. Advances in Structural Engineering. 2012;15:1977-1988.

[19] Belleri A, Torquati M, Riva P. Seismic performance of ductile connections between precast beams and roof elements. Mag Concrete Res 2014. p. 553-562.

[20] Belleri A, Torquati M, Riva P, Nascimbene R. Vulnerability assessment and retrofit solutions of precast industrial structures. Earthq Struct. 2015;8:801-820.

[21] McKenna F, Fenves GL. OpenSees Manual. Pacific Earthquake Engineering Research Center; 2013.

[22] Ibarra LF, Medina RA, Krawinkler H. Hysteretic models that incorporate strength and stiffness deterioration. Earthq Eng Struct Dyn. 2005;34:1489-1511.

[23] Fardis MN, Biskinis D. Deformation capacity of RC members, as controlled by flexure or shear. In: Proceedings of International Symposium on Performance-based Engineering for Earthquake Resistant Structures honoring Prof. Shunsuke Otani. T. Kabeyasawa, H. Shiohara. University of Tokyo2003. p. 511-530.

[24] Magliulo G, Capozzi V, Fabbrocino G, Manfredi G. Neoprene-concrete friction relationships for seismic assessment of existing precast buildings. Eng Struct. 2011;33:532-538.

[25] CEN. Eurocode 8: design of structures for earthquake resistance - Part 1: general rules, seismic actions and rules for buildings. EN 1998-1. Brussels, Belgium; 2005.

[26] Luzi L, Hailemikael S, Bindi D, Pacor F, Mele F, Sabetta F. ITACA (ITalian ACcelerometric Archive): A web portal for the dissemination of Italian strong-motion data. Seismol Res Lett. 2008;79:716-722.

[27] CEN. Eurocode 8: Design of structures for earthquake resistance - Part 3: Assessment and retrofitting of buildings. European Standard EN 1998-3-2005, Comité Europèen de Normalisation, Bruxelles, Belgium. 2005.

[28] Carydis P, Castiglioni C, Lekkas E, Kostaki I, Lebesis N, Drei A. The Emilia Romagna, May 2012 earthquake sequence.The influence of the vertical earthquake component andrelated geoscientific and engineering aspects. Ingegneria Sismica. 2012;2-3. 